\title{
FAMILIAL PERONEAL MUSCULAR ATROPHY AND ITS ASSOCIATION WITH THE FAMILIAL ATAXIAS AND TREMOR AND LONGEVITY
}

\author{
BY
}

\section{RAYMOND HIERONS}

\section{From the Department of Neurology, King's College Hospital, and the National Hospital, Queen Square, London}

For more than half a century descriptions of familial disorders of the nervous system showing marked differences in the clinical pattern of the malady from one member to another have been recorded. Hodge (1897) described three sibs suffering from Friedreich's ataxia, who had various combinations of muscular atrophy and loss of the posterior columns. Marie (1906) and Boveri (1911) were probably the first to emphasize that in families showing atrophy of the peroneal muscles and hypertrophy of the peripheral nerves occasional cases of familial ataxia could occur. Spiller (1910) discussed the problem in detail and reported two cases of Friedreich's disease with muscular wasting similar to that in peroneal muscular atrophy. One of these cases was studied histologically, when, in addition to the characteristic findings of Friedreich's disease, changes were also evident in the peripheral nerves. Similarly, Biemond (1928) described five families with peroneal muscular atrophy, in which isolated cases of Friedreich's ataxia occurred. In one of these families a single case of hypertrophic interstitial polyneuritis was discovered, thus suggesting a relationship between this condition and that described by Dejerine and Sottas. Greenfield (1912), van Bogaert and Moreau (1940), and Ross (1942) also described this relationship of Friedreich's disease with peroneal muscular atrophy. Spillane (1940) described a family with 21 members, 16 of whom showed signs of the so-called Roussy-Levy syndrome which includes pes cavus, absent reflexes, occasional wasting of the hypothenar muscles, kyphoscoliosis, and, rarely, dementia. Four cases had an explosive type of dysarthria; two or perhaps three showed signs of typical peroneal muscular atrophy and one showed Friedreich's ataxia. Roth (1948) describes this same association of Friedreich's ataxia with the CharcotMarie-Tooth disease, together with a marked tendency to psychopathic behaviour in one of the families. He discusses the variability from one member to another on the basis of Haldane's (1941) hypothesis that three or four genes produce each "different" disease and that each gene is responsible for the onset at a particular age. As the result of the effect of genetic modifiers on the main gene and multiple allelomorphs further differences in the clinical pattern can occur.

Turning now to the question of the existence, as a separate entity, of Marie's hereditary ataxia, Holmes (1907) expressed the view that " neither clinical nor pathological experience justifies its retention as the descriptive title of a form of disease ", urging that it could not be distinguished from Friedreich's ataxia. Bell and Carmichael (1939), after surveying over 1,000 cases from the literature and 100 of their own, produced strong evidence for the unity of the Friedreich and Marie types. In addition they pointed out a clinical relationship between the hereditary ataxias and hereditary spastic paraplegia. Although Sjögren (1943) attempted to cast doubts on these conclusions, a recent clinical study by Schut (1950) of 22 cases of hereditary ataxia descended from a common ancestor revealed examples of these three clinical conditions. He examined five cases pathologically with Haymaker and found various combinations of the changes in Friedreich's ataxia, olivopontocerebellar atrophy, and bulbar palsy (Schut and Haymaker, 1951).

Even in such an apparently clearly defined disease as Leber's optic atrophy, Ferguson and Critchley (1928) described a family in which, in addition to typical cases, others occurred with pyramidal signs, posterior column signs, or even dysarthria. This suggested a transition between Leber's disease and Marie's ataxia. Bickerstaff (1950) described a family with 25 affected members suffering from spastic paraplegia, two having in addition retrobulbar neuritis progressing to optic atrophy. Van Leeuwen and van Bogaert (1949) have also described this association of retro-bulbar neuritis with the hereditary ataxias.

The family which I now describe illustrates this 
variation from one member to another. Its chief interest is that a large number, including quite a few affected members, achieved considerable distinction, the most famous being reformers, writers, judges, admirals, or generals. From the literature, one forms the impression that these disorders are frequently associated with inadequate or psychopathic tendencies. Due to the abundance of famous names in this family, accurate genealogical details can be given over more than eight generations. As I have not found any record of the disease affecting the family before this, I have confined my study to these generations. Of the earlier generations, very brief clinical details are available from the records kept by a member of the family who was himself a medical man. His notes were probably made at the end of the last century, when in addition to being medical director of one of the armed forces, he was a medical adviser to Queen Victoria. The dia nostic label which he gave to the malady w " hereditary muscular atrophy".

The family tree is shown in the Figure.

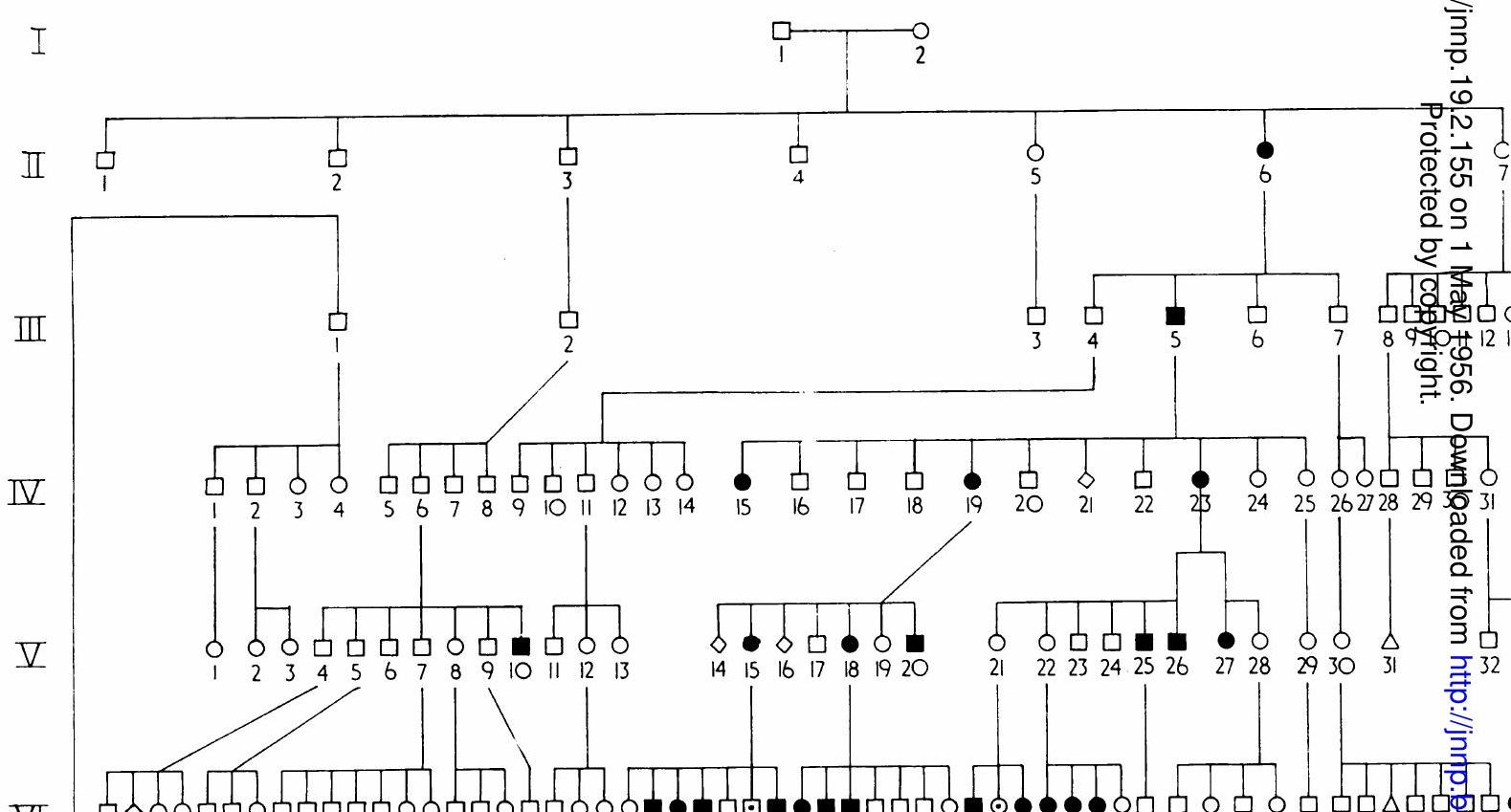

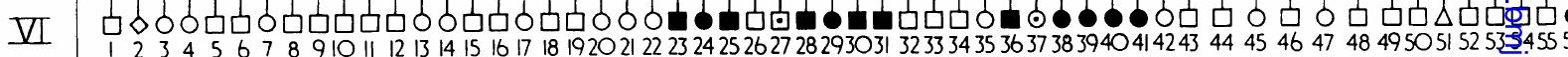
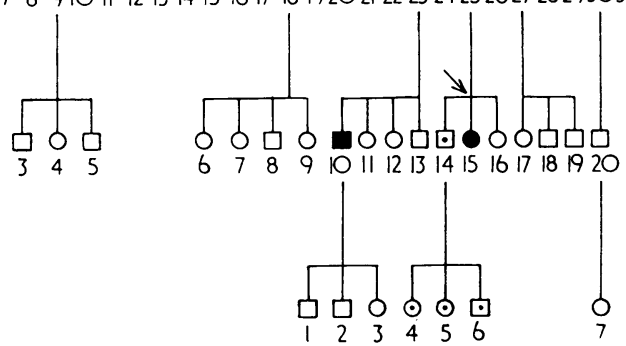
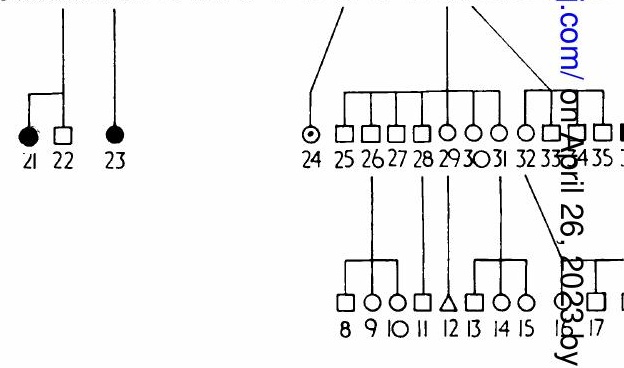


\section{The Affected Members}

Case 1 (VII 15). - The propositus, a wuman aged 36, was admitted to the National Hospital (No. 32096) in July, 1952, under the care of Dr. Macdonald Critchley. In infancy she suffered from meningitis during which she was unconscious for several days. This may explain why she was always considered to be less intelligent than the rest of the family and as a result was sent to a boarding school where examinations were not considered important. She has, however, been able to manage a clerical job for several years.

During childhood she was never able to walk on her toes and at the age of 18 several orthopaedic operations were carried out on her deformed feet, including division of both Achilles tendons. Her handwriting has always been shaky and her walking unsteady and both have deteriorated over the years.

After her mother's death a year before admission, symptoms of anxiety and depression developed and this was the chief reason for her coming into hospital.

Examination revealed no abnormalities of cranial nerve function except for first degree vestibular nystagmus to both sides and also on upward deviation. In the motor system there was wasting of the small muscles of the hands, the lower forearms, and also below the knees. In addition, tremor of both hands at rest and increased by movement, while rapid alternating movements were slowly and irregularly carried out, especially on the right. Reflexes were present except for the ankle jerks, and both plantar responses were extensor. Sensory testing revealed that appreciation of pain and light touch was impaired below the knees while vibration was not appreciated below the costal margins, although passive movements of fingers and toes were accurately assessed.

While in hospital, her symptoms of anxiety and depression improved and she was able to return to work, but she was readmitted in January, 1953, because of their recurrence. No appreciable change was noted in the physical signs. She was seen by Dr. C. S. Hallpike who confirmed spontaneous nystagmus without any appreciable change with the head back to either side. Cochlear function was normal and caloric responses were found to be brisk and equal. He detected an unusual alteration in optokinetic nystagmus which was abolished to the left and reduced to the right, suggestivc of a high brain-stem lesion.

This case appeared to have a basis of peroneal muscular atrophy with the addition of nystagmus, static tremor increased on movement, and bilateral cerebellar signs.

This patient's younger sister (VII 16) aged 29 had no special symptoms but had high arched feet and diminished appreciation of vibration at the ankles.

Case 2 (VI 28).-This was a male, aged 73. During childhood he tended to catch his toes in walking and he recalls that while still a midshipman in the Navy he stumbled on several occasions in getting from one boat to another and as a result fell into the sea. At about the age of 35 he became rather more unsteady and describes how this forced him to give up his favourite recreation of walking in St. James's Park after his duties at the Admiralty, fearing that he might be thought to be the worse for drink. Soon afterwards a physician noticed muscular wasting of the hands. As the weakness of his feet increased he was fitted with toe springs and with these hidden under his trousers, he was able to continue in the Navy, reaching the rank of Vice-Admiral at the age of 48. His retirement at this age was not caused by his complaint. After his retirement he was ordained as a clergyman and in spite of increasing weakness of the hands continued as the vicar of a busy parish for more than 20 years until a recent fall caused a fracture of the neck of the femur.

On examination, his speech and intellectual functions were normal. Fine horizontal nystagmus on lateral deviation to either side and reduced visual acuity in the right eye from cataract were the only abnormalities of cranial nerve function found. Wasting of the small muscles of the hands, especially of the first interosseous spaces, and to a slight degree of the lower forearms, but marked in the legs with pes cavus, was found. Fasciculation was not observed. Tremor was obvious in the fingers, abolished at rest but increased on voluntary movement. Rapid alternating movements in the upper limbs were carried out irregularly. Reflexes were all obtained with difficulty; plantar responses were extensor. Sensory testing revealed slight impairment to light touch and pain below the knees, defective appreciation of passive movements at the toes, and loss of vibration sense below the costal margins. No defect to any form of sensation was found in the upper limbs. The peripheral nerves were not thickened. Because of the recent fracture, it was not possible to see him standing or walking.

The condition in this case appeared to be peroneal muscular atrophy with the addition of bilateral extensor plantar responses, nystagmus, and tremor.

Case 3 (VI 25). - This was an elder brother of Case 2 and father of Case 1, and was aged 78. He was not a very reliable witness and insisted that he was not suffering from the family trouble. He attributed his unsteadiness in walking to an amputation of the left arm disturbing the centre of gravity. Notes by his doctor father, however, contain the brief reference that his feet were affected, probably when he was about 15 years old. In spite of this he was able to enter the Navy and rose to the rank of Commander until the loss of his arm forced him to retire while still under the age of 40 , when he first noticed slight weakness of the remaining hand.

Examination showed evidence of mild intellectual impairment; otherwise there was no abnormality of special senses or cranial nerve function. There was no nystagmus. The remaining hand and both legs were wasted similarly as in Case I. There was no tremor, however, nor were there signs of incoordination in the right arm, but in the lower limbs there was marked ataxia probably due to impairment of postural sense. Reflexes were normal except for the ankle jerks which were absent.

Although the patient was unreliable as a sensory witness it seemed that appreciation of passive movements 
was impaired at the toes and vibration sense lost below the iliac crests.

There was a slight degree of scoliosis in the upper dorsal spine.

He had marked Rombergism and, when walking, bilateral foot drop and a high-stepping type of gait.

This seemed to be a typical case of peroneal muscular atrophy.

Case 4 (VI 38). - This woman, aged 77, was the wife of a general. Until about the age of 40 she claims that she was normal in every way. At this time she first found difficulty in walking which was followed by weakness of the hands. These symptoms have gradually increased and in recent years tremor of the hands has developed.

Examination showed wasting of the small muscles of the hands and also below the knees. A static tremor of the hands very like that of Parkinsonism was present but was much accentuated by movement. Below the knees, sensibility to pain and light touch were impaired together with postural loss at the toes.

This patient appeared to be suffering from peroneal muscular atrophy with the addition of tremor.

Case 5 (VII 23). - This woman, aged 39, was the only daughter of Case 4. About 10 years earlier, while serving as a V.A.D. in an ophthalmic department, she first noticed tremor of the hands. In recent years she has found increasing difficulty in walking.

Physical signs included tremor of the outstretched hands, not increased by movement, clawing of the toes and severe weakness of dorsiflexion of both feet. Unlike the previous cases, no wasting or weakness was observed in the upper limbs. The only sensory impairment was loss of vibration sense below the iliac crests.

This case could perhaps be classified as peroneal muscular atrophy confined to the lower limbs with the addition of tremor of the hands.

Case 6 (VII 21).-This patient, aged 36, was the daughter of a High Court judge who was himself afflicted with the malady from adolescence until his death at the age of 66 .

She began to have difficulty in walking at about the age of 8 and noticed weakness of the hands a few years later.

Examination revealed marked wasting of the small muscles of the hands and marked wasting below the knees. The knee and ankle jerks were absent and no response was obtained from plantar stimulation but the power of dorsiflexion of the feet and toes was lost. Postural loss at the toes appeared to be the only sensory defect.

This appeared to be a typical case of peroneal muscular atrophy.

The following three cases are sisters who were also examined, though unfortunately not under ideal circumstances.

Case 7 (VI 39).-A woman, aged 72, has been unsteady in walking since childhood and, at the age of 30 , operations were performed on both feet. Since then the hands and feet have slowly become weaker and for 20 years she has been obliged to wear walking irons. An arthrodesis the left ankle was performed a few years ago whicf improved her walking considerably.

Abnormal physical signs included first degree vest竞 bular nystagmus to either side, and some wasting below the knees, wasting of the hands with clawing of the fingers which was more marked than in any other case in this series. The left ankle joint was ankylosed while on the right there was paralysis of the dorsiflexors of the foot and only feeble plantar flexion. Tremor was absent at rest but occurred at the termination of movement; more especially in the left arm. The knee jerks were obtained with difficulty; ankle reflexes were absent and

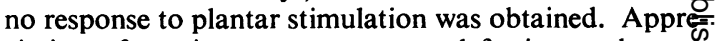
ciation of passive movements was defective at the toess and appreciation of vibration lost at least to the kneeß Gait was of the high stepping type.

This appeared to be a case of peroneal muscular atrophy with the addition of nystagmus and sligi intention tremor.

Case 8 (VI 40). - This woman was 71 years of age. A a child she is said to have had deformed feet but was otherwise quite normal until about the age of 60 . Sin then movements of the hands have become clumsy and in the last five years she has noticed weakness of the muscles of both hands.

Examination revealed fine lateral nystagmus to

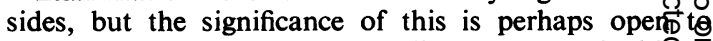
doubt as, only a few months earlier, a cataract had bet extracted from the left eye. There was wasting in the first interosseous space on both sides similar to thas it the other cases, and in the lower limbs bilateralgyes cavus. Muscular power, except for weakness of the interossei, was normal, as were the reflexes, althougg both plantar responses were equivocal. No defect $\dot{\text { qf }}$ any form of sensation was found.

The unusual feature of this case is that until the age of 60 , probably the only abnormality was the pes cavu施 the wasting of the hands having occurred since then.

Case 9 (VI 41). - A woman, aged 70, from about the age of 20 had noticed weakness of the legs, slight u局 steadiness in walking, and tremor of the hands. Since then the weakness has increased.

Examination revealed no nystagmus. There wa्ध wasting and weakness of the interossei of both hands. and a static tremor of the fingers which was increased movement. Wasting below the knees was marked and there was bilateral pes cavus. All reflexes were preser and equal and plantar responses flexor. The only defect. found on testing of sensation was loss of appreciation 8 vibration at least up to the knees.

This seemed to be a typical case of peroneal musculat atrophy with the addition of tremor.

- Case 10 (VI 23).-A retired colonel, aged 80, has use toe springs for 30 years. Only a very brief examination. was possible. The hands showed wasting of the smads muscles; tremor was absent and coordination normab in the upper limbs. Nystagmus was not observed. Ga: was suggestive of bilateral foot drop with some ataxia. 
This patient's eldest son (VII 10), a clergyman, undoubtedly suffers from the malady but it is not his parents' wish that I should see him.

The following members of the family were examined and no abnormal signs found:-VI 27 aged 76, VI 37 aged 78, VII 14 aged 35, VII 24 aged 30 , VIII 4 aged 11 , VIII 5 aged 9, and VIII 6 aged 8.

\section{Distinguished Persons in the Family}

One rather unexpected finding in a familial disorder of this nature is the number of distinguished individuals in the eight generations which I have investigated. Those mentioned here are described in the Dictionary of National Biography and naval and military biographies and it is highly probable that others achieved fame in their own time.

It is not known which of the two original members introduced the disease. The origin of Elizabeth Heyw-d (I 2) can be traced, according to Burke's Peerage, to Peter Heyw-d who was born in 1104. Charles Caldw-1 (I 1) was a solicitor in customs in Dublin and came originally from Scotland.

The first affected individual of whom I have any record is II 6. Biographical accounts of two of her brothers are contained in the Dictionary of National Biography: II 1 was a barrister and writer, while the other, II 2, was Admiral of the Blue (when the British Navy was divided into two sections, Blue and Red) and was knighted. He retired on account of his health at the beginning of the Napoleonic wars but I have not been able to find whether from this malady or not. Judged by his handwriting in his dispatches to the Admiralty he does not appear to have suffered from tremor.

Many descendants of II 2 are alive and although they have not been directly approached I have not heard of any cases of the malady existing; one has been created a baronet.

III 3, a knight and a general, became well known after retirement as a writer and reformer, advocating that only a State bank should issue currency-a revolutionary view in the early nineteenth century.

III 6 was knighted and was a general; in 1813 he drove the Americans from Buffalo and after retiring was Governor of the West Indies.

IV 1 was a scholar and fellow of Jesus College, Oxford.

IV 2 was a Member of the House of Assembly, Jamaica.

IV 8, a Commodore, R.N., was A.D.C. to Queen Victoria and was a C.B.

V 4 was a Doctor of Civil Law and High Sheriff of Dublin.
V 15 was the wife of the naval surgeon referred to earlier whose notes provide the basis of this paper. V 22 was the wife of an Archbishop of Dublin.

VI 12 was an O.B.E., VI 27 a general, and VI 36 a knight and judge. VI 28 (Case 2) was an admiral and later a clergyman, and VI 23 (Case 10) a colonel. VII 1, was the first baronet.

VII 14 was a captain R.N. at the age of 36 , and VII 28 the first baronet.

VIII 8 was a knight and judge.

\section{Longevity}

The life span of many members of this family seems to have been longer than might have been expected for the eighteenth and nineteenth centuries, even allowing for their high economic and social status.

The earliest members died at the age of 69 and 60 years. Of the second generation, who lived between 1730 and 1820, four survived to an age of over 70 and one to over 80 years. Excluding two female members (their age is not known) the average duration of life in this generation was 77 years. In the third generation three lived to be over 70 and four to over 80 years. Excluding those killed in the Peninsular War, whose ages are not known (three females and one male), the average age of this generation is 68 years. Three members of the fourth generation (1800-1900) lived to be more than 70 , four to be over 80 , and one to the age of 94 years of age. Excluding several who died in the first few weeks of life but not those who died before puberty or in battle, the average life span was 62 years (six females are excluded due to inadequate records of their ages).

In the fifth generation, five were over 70 years at death, two over 80, and four over 90 . Excluding five who died in the first year and two whose age is not recorded, the average duration of life was 71 years. Two members of this generation are still alive. Of the sixth generation, 24 lived to over 70 and six to over 80 , and many of them are still alive.

\section{Variability of the Clinical Features}

It was possible to examine most of the living affected members except VII 10 and VII 36 and 37 who may be affected but could not be traced.

The basis of these cases seems to be peroneal muscular atrophy. Extensor plantar responses, which are not a feature of this condition, were found in two cases and nystagmus in three, possibly four cases. Tremor of the hands at rest was observed in three and in several others on activity. Slight cerebellar signs in the upper limbs were present in three. These features are not generally accepted as 
TABLE

BLOOD GROUPS OF THE CASES STUDIED

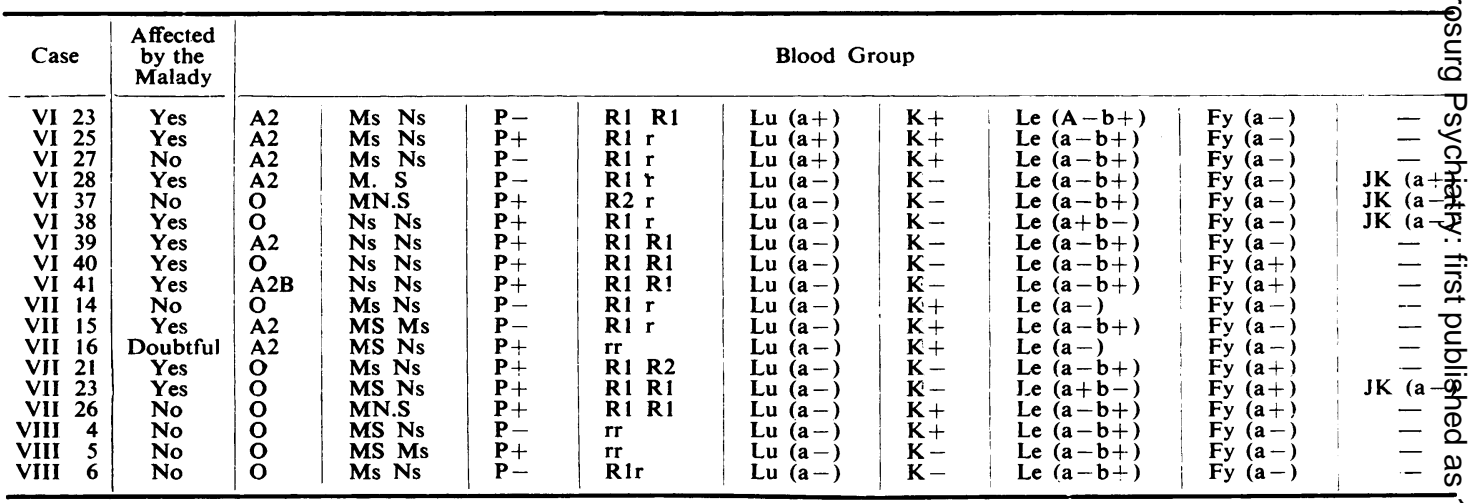

Antisera used : anti-A. -Al, -B ; anti-M, -N, -S; anti-P; anti-C, -c, -Cw, -D. -E, -e ; anti-Lua ; anti-K ; anti-Lea, -Leb ; anti -Fy $\vec{b}$ and, occasionally, anti-JKa.

being part of peroneal muscular atrophy but rather of the familial ataxias.

The age of onset of the disease in the cases I saw personally varied as follows :-

\begin{tabular}{|c|c|c|c|c|c|c|}
\hline Decade .. & .. & $1 s t$ & 2nd & 3rd & 4th & 6th \\
\hline Number of Cases & .. & 3 & 3 & 2 & 1 & 1 \\
\hline
\end{tabular}

The last of these (Case 8) had deformed feet in childhood although weakness and wasting only developed after the age of 60 .

\section{Inheritance}

From the family tree it can be seen that 12 affected members produced 22 affected offspring and 33 unaffected (excluding those who died in infancy). The condition is clearly due to a dominant Mendelian character. The penetrance of the gene is incomplete, and, as has been shown in the previous section, its expressivity is variable.

In the case of $\mathrm{V} 10$ it may well be that the difficulty in walking which the patient is said to have had may have been due to another disease as it seems unlikely that the condition could have "skipped " so many generations.

An affected parent was traced except for the Cases VI 39, 40, and 41 where the mother was said to have had "weak feet" but who was not otherwise significantly disabled.

In the literature on this subject, men seem to be three times more frequently affected than women. In this family, however, there is a slight preponderance of females (18 out of 32 ).

The descendants of III 7 have remained unaffected in spite of intermarriage on several occasions. In the first place III 3 married IV 26, their grandson VI 49 married V 3, and finally VII 32 married IV 30.
The blood groups of the affected member were determined together with those of some un affected members of the family that I had the opportunity to examine (Table). The blootb groups do not give any evidence for or agaigisit linkage of their genes with the peroneal atrophy ge्षि

\section{Summary}

으음

In familial disorders of the nervous system variations in the disease from one member to anothe have been described. The chief interest of this family is that a large number of members hâve achieved distinction in spite of increasing disabifity? In addition, they seem to have had an increase 8 expectation of life.

My thanks are due to Dr. Macdonald Critchley fo his encouragement in investigating this family. I am indebted to Dr. R. R. Race, of the Medical Research Council Blood Group Research Unit, and Dr. Eliot Slater for criticism and suggestions.

\section{REFERENCES}

Bell, J., and Carmichael, E. A. (1939). “ On Hereditary Ataxia and Spastic Paraplegia." Treas. hum. Inher., 4, Pt. 3, 141. Bickerstaff, E. R. (1950). Journal of Neurology, Neurosurgery añ
Psychiatry, 13, 134.

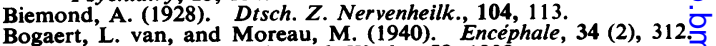
Bogaert, L. van, and Moreau, M. (1940). 58, 1238.

Ferguson, F. R., and Critchley, M. (1928). J. Neurol. Psychopath. 9, 120.

Greenfield, J. G. (1912). Proc. roy. Soc. Med. (Sect. Neurol.), 5, 75

Haldane, J. B. S. (1941). J. Genet., 41, 141, 149.

Hodge, G. (1897). Brit. med. J., 1, 1405.

Holmes, G. (1907), Brain, 30, 545 .

Leeuwen, M. A van, and Bogaert, L van (1949). Ibid. 72, 340. Marie, P. (1906). Rev. neurol. (Paris), 14, 557.

Marie, P. (1906). Rev. neurol. (Paris), 14, 557.

Ross, A. T. (1942). J. nerv. ment. Dis., 95, 680.
Roth, M. (1948). Brain, 71, 416.

Schut, J. W. (1950). Arch. Neurol. Psychiat (Chicago), 63, 535. -, and Haymaker, W. (1951). J. Neuropath. clin. Neurol., $\$$ 183.

Sjögren, T. (1943). Acta psychiat. (Kbh.), Suppl. 27

Spillane, J. D. (1940). Brain, 63, 275.

Spiller, W. G. (1910). J. nerv. ment. Dis., 37, 411. 